\title{
The Effect of National Culture on Total Quality Management and Organizational Performance
}

\author{
${ }^{1}$ Rabiul Islam and ${ }^{2}$ Abdullah ALNasser \\ ${ }^{1}$ School of Economics, Finance and Banking, \\ ${ }^{2}$ School of Business Management, \\ College of Business, University Utara Malaysia, 06010 UUM, Sintok, Kedah, Malaysia
}

Received 2013-07-24, Revised 2013-08-15; Accepted 2013-08-29

\begin{abstract}
Soft-hard total quality management comprises of the utility of human resource management-style personnel policies to product commitment to quality and a management ideology that supports cultural change maxims, continuous improvement and customer satisfaction. The aim of the study is to determine the mediator effect of national culture on the relationship between soft-hard total quality management and organizational performance in municipalities. A quantitative research design was adopted to collect data. Multiple regression analysis method was used to conduct this study. The findings of the study will contribute to both theory and practice. The results of this study have important contributions and implications for practitioners and policy-makers in these five developing countries. Empirical evidence revealed that soft-hard total quality management has relationship with performance. The findings also implied that soft-hard total quality management has positively relation with performance and there is difference in organizational performance mean between all these countries.
\end{abstract}

Keywords: Mediator Effect, National Culture, Quality Management, Organizational Performance

\section{INTRODUCTION}

Hall (1989) proposed a set of parameters to study cultures comprising a dimension that extends from highcontext to low-context and from the low-context to the high-context category. Hall (1989) stated that highcontext communication refers to a type of communication that relays not just verbal communication and includes behavior and para-verbal cues as according to him, "meaning and context are inextricably bound up with each other (Hall, 1989). Hence, for communication understanding, one should examine the meaning coupled with the context and the code. Context is referred to as the situation, background or surrounding that is linked to the event, situation or even the individual. High context communications also entails drawing on the common knowledge of the parties to the communication.
Total Quality Management (TQM) practices are being widely adopted by contractor companies to solve problems regarding quality in the construction industry particularly to satisfy the needs of the customers. It is no surprise that TQM has now become the major business strategy in current management and has currently been taken up by companies around the globe. The construction industry is being considered as comparatively having one of the poorest quality emphases among different manufacturing and service sectors.

According to Hall (1989), cultures from high-context to low-context are represented by the following countries; Japan, Arab countries, Greece, Spain, Italy, England, France, North America, Scandinavian Countries and German-speaking countries. Hall (1989) added that people from low-context cultures possess a communication style that is consistent with feelings while people from high-context culture allow the relay of

Corresponding Author: Rabiul Islam, School of Economics, Finance and Banking, College of Business, University Utara Malaysia, 06010 UUM, Sintok, Kedah, Malaysia 
message without directly addressing the problem. In case of conflict, high-context cultures are known to make use of indirect, non-confrontational and unclear language, that depends on the listener's or the reader's skill in understanding the meaning from the context. On the other hand, low-context cultures are more inclined to be direct, confrontational and candid approach to guarantee that the listener got the correct message intended.

Similarly, other authors like Gudykunst et al. (1996) refers to high context communications as indirect, unclear, harmonious, reserved and understated while to low-context communication as direct, accurate, dramatic, open, clear and highly dependent on feelings and true intentions.

House et al. (2004) conducted the GLOBE study involving 62 different cultures and 127 investigators in societies all over the globe through the years from 19941997. The data collection tool used was the survey questionnaire which was distributed to 17,000 middle managers in a total of 951 organizations throughout 3 particular industries namely banking, food processing and telecommunication.

Trompenaars (1993) created a model in his attempt to study national culture and its impact on business practices through gathered data from 15, 000 managers from 47 countries. Trompenaars and Turner (1997) proceeded to conduct a study with a fellow researcher on the basis of data gathered from 30, 000 managers working in multinational and international companies hailing from a total of 45 countries. The study examined the impact of national culture and other factors including occupation (Woolliams, 1997). Each dimension was provided by examples and outcome expectations for both management and organization. Trompenaars came up with seven cultural valuing dimensions, of which five are universalism-particularism, achievement-ascription, individualism-collectivism, affectivity-neutrality and specificity-diffuseness and were taken from the study conducted by Parsons and Shils (1951) while the remaining dimensions are adopted from other researchers (Rotter, 1966).

Hofstede's influential work in the field of culture resulted in the researchers' applications in the field even today. He is successful in highlighting cross-cultural analysis in the field of international business. Despite the criticisms it gained including reliance on old data, lack of inclusion of the Eastern bloc among others (Schwartz, 2008; Fang, 2010), it is still viewed as the most comprehensive and most valued work in the culture domain (Sondergaard, 1994) with citations of his work over 54, 000 times up until 2010 (Tung and and Verbeke, 2010). Either, Hofstede's dimensions which have been cited $(14,750)$ times as of February 2010 other reason for using the Hofstede specific four dimensions to validate his claim of homogeneity of Arab culture and their effect in their relations between Soft-Hard TQM and Performance in the municaplities. Other reason, Hofstede (1984), applied all of his four deminsions that is (power distance, uncertainty avoidance, individualism/collectivism.) on these five countries, while he did not apply the fifth deminsion (long term oriented) on these countries, for the previos reasons his typology of his four deminsions will be used in this research.

The municipalities around the world have a number of common tasks and functions, such as public hygiene, waste management and control of environmental health. The municipalities are also considered part of local governments with their activities vary from one country to another. For example, in some countries they are responsible for housing and transportation within the cities, water and sanitation. While in other countries these activities are assigned to other sectors of government. Most municipalities rely on government support, self-sources such as taxes and fines, donations and other sources.

Many developing countries suffer from ineffective and poor performance of their public sectors, particularly service sectors that have direct relationship with the citizens such as municipalities. There are many criticisms directed to municipalities' performance in the media. While, there is few researches dealt with their performance problems and solutions. However, there are differences in these countries in the stage of improving their public sectors performance by implementing Total Quality Management (TQM) as mention early. This research aims to compare between five public sectors in five developing countries; Egypt, Jordan, Qatar Saudi Arabia and Turkey. The objective is to discover differences and similarities between them and to measure the effect of national culture on the relationship between soft-Hard TQM and performance.

Researchers have consistently debated on the TQM practices categorization (Samson and Terziovski, 1999). Initially, the Malcolm Baldrige National Quality Award (MBNQA) was utilized as the most popular framework and was considered as a reliable TQM measure (Lee and Wang, 2003). In the present research, four out of five TQM soft factors and all hard TQM factors are adopted from the seven factors categorized in the MBNQA. The selection of soft and hard TQM factors lies is based on their significance to the public sector-other soft and hard TQM factors are more suitable to the private sector. On the basis of literature reviewed pertaining to quality management in the service sector organizations, some TQM factors have been investigated. 


\section{MATERIALS AND METHODS}

The theoretical framework was shown in the following Fig. 1.

The study model is depicted in Fig. 1 where four latent variables are presented namely Soft Total Quality Management, Hard Total Quality Management, National Culture and Organizational Performance. Soft TQM is explained by a total of five variables which are management commitment, supplier relationship, employee relations, strategic planning, education and training customer focus. On the other hand, Hard TQM is explained by process management, quality information and analysis and strategy planning. Organizational performance is explained by four variables namely financial element, customer, internal process and employee and National Culture is presented by four variables which are Hofstede (1984) popular cultural dimensions including power distance, uncertainty avoidance, individualism and masculinity.

\subsection{Independent and Dependent Variables Relationships}

In this study, hypothesis testing is done using regression model. The first part of the hypothesis test will be concern with the direct relationships between all the independent variables and the dependent variable which is the organizational performance. After the direct relationships have been investigated the moderating effect of culture is tested. The first model will test the relationship between all the independent variable except without the moderators while the second model tests the all the soft and hard TQM variable along the moderators as independent variable to test initially whether these variable are moderator. Baron and Kenny (1986) suggested that to test whether a variable should be included as a moderator it must be included in the equation as an independent variable and test its direct effect on the dependent variable. If the variable is found to be significant as an independent variable then transformation is need to test it indirect effect. Therefore the first model will test the direct relationship between soft and hard TQM practices with the organizational performance Equation 1:

$$
\begin{aligned}
& 0 \mathrm{P}=\mathrm{a}_{\mathrm{i}}+\mathrm{b}_{1} \mathrm{TM}+\mathrm{b}_{2} \mathrm{ER}+ \\
& \mathrm{b}_{3} \mathrm{EAndT}+\mathrm{b}_{4} \mathrm{SR}+\mathrm{b}_{5} \mathrm{PM}+\mathrm{b}_{6} \mathrm{QI}+\mathrm{b}_{7} \mathrm{SP}+\varepsilon
\end{aligned}
$$

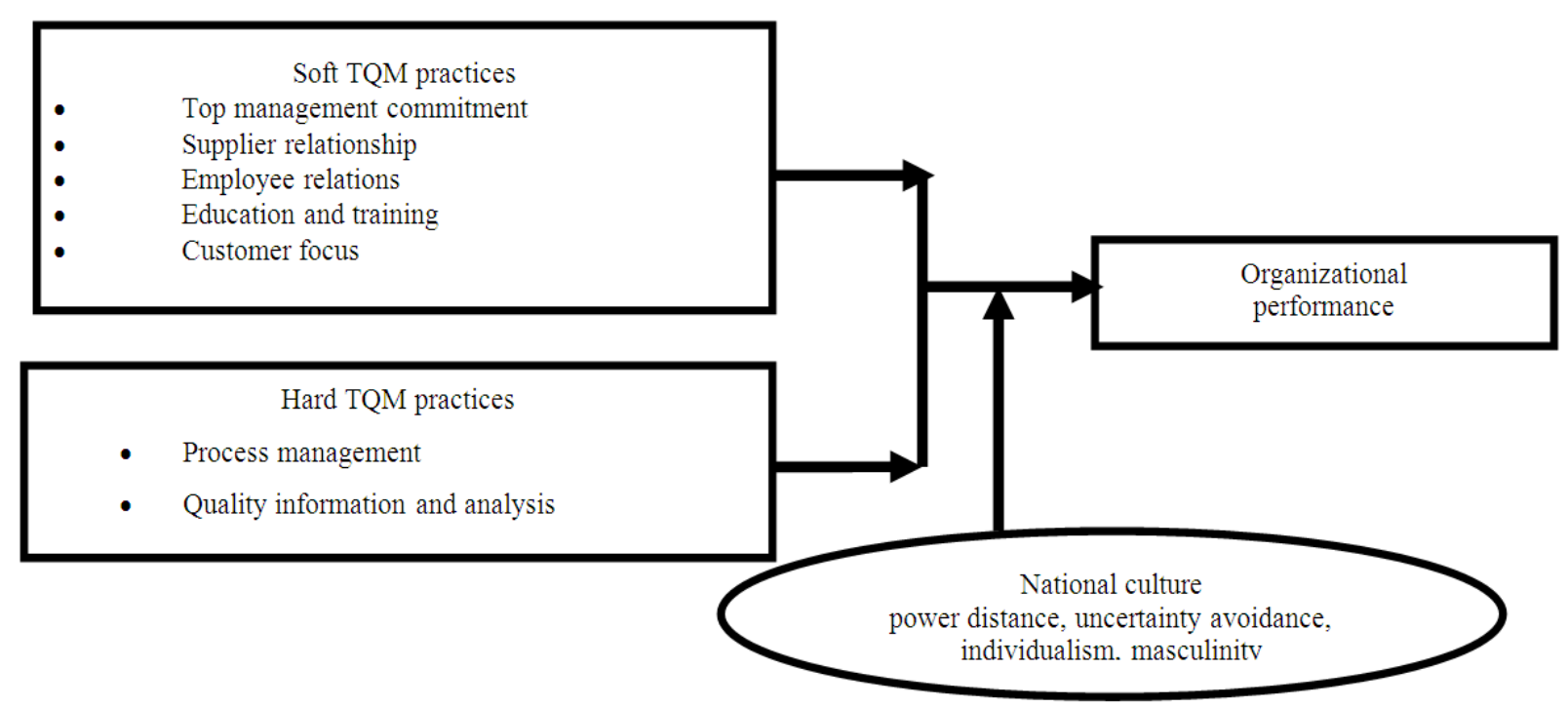

Fig. 1. Theoretical framework 


\section{RESULTS}

\subsection{Descriptive Analysis}

Descriptive analysis describes conditions, populations and phenomena as they are the purpose of descriptive statistics are to summarize or describe a set of quantitative data. Researchers use these statistics to describe or characterize the population or sample being studied. Basically, descriptive statistics refers to means, ranges and numbers of valid cases of one variable. Table 1 shows the descriptive statistics of all principal constructs while.

In this study, the mean and standard deviation for the soft TQM practices were in the range of 3.94 to 4.12 and in the range of 1.07 to 1.11 , respectively. The mean for Hard TQM practices was in the range of 4.05 to 4.06 and standard deviation was in the range of 1.03 to 1.06 . In this study, the four dimensions of Culture mean were in the range of 4.03 to 4.22 while the standard deviation ranged from 0.88 to 0.98 . Lastly, the mean of the performance measure is 4.11 while its standard deviation was 0.96. The mean scores for all variables were moderately high. There were no low level mean scores. The moderate high mean scores imply that respondents agree that all variables influence the organizational effectiveness of an organization. Among the independent variables, employee relations have the highest mean compared to other variables while the lowest was for the education and training. However, the mean score for the moderator variable culture shows that the highest mean is for uncertainty avoidance while the lowest was for Masculinity. Even though the rest of the TQM practices were not as high as employee relation their mean scores of around 4.00 imply that these activities cannot be taken lightly.

The standard deviations for all variables seem to fall between 0.88 and 1.11 , which simply reflects the existence of considerable acceptable variability within the data set. The variation value indicates that all answers on the study variables were substantially different from one respondent to another, thus, signifying the existence of tolerable variances in responses.

Finally, the Skewness and kurtosis of the 13 constructs are well behaved in term of normality. The values of Skewness and kurtosis are between the ranges of -1 and +1 which indicate that there are no outlier or extreme values that might jeopardise the validity of the analysis. Consequently, all the thirteen constructs representing the four variables are ready for subsequent analysis.

\subsection{Correlations and Linearity}

Correlation analysis was performed for all thirteen constructs included in this study to understand the relationship between each of the constructs. The results of the correlation analysis are presented in Table 2 . The results of the correlation analysis prove the existence of the relationship between dependent and independent variables. For Table 2 it is clear that the correlation coefficients are significant and positive. The lowest correlation is between the culture construct Masculinity and the Quality information and analysis which was 0.34 . The highest correlation is between employee relations and customer focus which is 0.90 . According to Cohen's Guidelines of correlation strength any absolute correlation coefficient value between 0.3 and 0.49 is considered of moderate strength and any value higher than 0.5 is considered of high strength. The range of significant correlations was between 0.340 and 0.896 . The results of the correlation analysis reveal that correlation between both dependent variable and the moderating variable is significant and positive. Organizational Performance positively and significantly related to all the constructs ranging from as low as 0.37 (Masculinity) and the highest is the Employee Relations at 0.88 .

Table 1. Descriptive statistics of all principal constructs

\begin{tabular}{lllllr}
\hline Variable & Construct & Mean & Std Deviation & Skewness & Kurtosis \\
\hline Soft TQM practices & Top management commitment & 4.06 & 1.070 & -0.756 & 0.275 \\
& Supplier relationship & 4.01 & 0.960 & -0.855 & 0.571 \\
& Employee relations & 4.12 & 0.993 & -0.829 & 0.140 \\
& Education and training & 3.94 & 1.110 & -0.645 & -0.152 \\
\multirow{4}{*}{ Hard TQM practices } & Customer focus & 4.03 & 1.040 & -0.994 & 0.926 \\
& Process management & 4.06 & 1.030 & -0.381 & -0.148 \\
Culture & Quality information and analysis & 4.06 & 1.060 & -0.484 & -0.201 \\
& Strategic planning & 4.05 & 1.090 & -0.820 & 0.536 \\
& Power distance & 4.19 & 0.981 & -0.539 & -0.350 \\
& Uncertainty avoidance & 4.22 & 0.883 & -0.448 & -0.217 \\
Organizational performance & Organizational performance & 4.04 & 0.990 & -0.841 & 0.576 \\
& Masculinity & 4.03 & 0.957 & -0.454 & -0.045 \\
& & & 0.959 & -0.657 & 0.224 \\
\hline
\end{tabular}


Table 2. Correlation coefficient

\begin{tabular}{|c|c|c|c|c|c|c|c|c|c|c|c|c|c|}
\hline Construct & TM & SR & ER & $\mathrm{E} \& \mathrm{~T}$ & $\mathrm{CF}$ & PM & QI & SP & PD & UA & IND & MAS & $\mathrm{OP}$ \\
\hline$\overline{\mathrm{TM}}$ & 1.00 & & & & & & & & & & & & \\
\hline SR & $0.81^{*}$ & 1.00 & & & & & & & & & & & \\
\hline ER & $0.84_{*}^{*}$ & $0.79^{*}$ & $1.00_{*}$ & & & & & & & & & & \\
\hline $\mathrm{E} \& \mathrm{~T}$ & $0.73^{*}$ & $0.70^{*}$ & $0.84^{*}$ & 1.00 & & & & & & & & & \\
\hline $\mathrm{CF}$ & $0.81^{*}$ & $0.73^{*}$ & $0.90^{*}$ & $0.81^{*}$ & 1.00 & & & & & & & & \\
\hline PM & $0.70^{*}$ & $0.68^{*}$ & $0.77^{*}$ & $0.68^{*}$ & $0.75^{*}$ & 1.00 & & & & & & & \\
\hline QI & $0.76^{*}$ & $0.70^{*}$ & $0.83^{*}$ & $0.69^{*}$ & $0.85^{*}$ & $0.77^{*}$ & 1.00 & & & & & & \\
\hline SP & $0.78^{*}$ & $0.66^{*}$ & $0.85^{*}$ & $0.72^{*}$ & $0.88^{*}$ & $0.78^{*}$ & $0.91^{*}$ & 1.00 & & & & & \\
\hline PD & $0.64^{*}$ & $0.60^{*}$ & $0.68^{*}$ & $0.59^{*}$ & $0.67^{*}$ & $0.69^{*}$ & $0.55^{*}$ & $0.62^{*}$ & 1.00 & & & & \\
\hline UA & $0.49^{*}$ & $0.47^{*}$ & $0.63^{*}$ & $0.59^{*}$ & $0.55^{*}$ & $0.58^{*}$ & $0.47^{*}$ & $0.53^{*}$ & $0.67^{*}$ & 1.00 & & & \\
\hline IND & $0.69^{*}$ & $0.69^{*}$ & $0.80^{*}$ & $0.73^{*}$ & $0.74^{*}$ & $0.66^{*}$ & $0.73^{*}$ & $0.73^{*}$ & $0.62^{*}$ & $0.63^{*}$ & 1.00 & & \\
\hline MAS & $0.42^{*}$ & $0.44^{*}$ & $0.45^{*}$ & $0.52^{*}$ & $0.45^{*}$ & $0.38^{*}$ & $0.34^{*}$ & $0.38^{*}$ & $0.56^{*}$ & $0.53^{*}$ & $0.51^{*}$ & 1.00 & \\
\hline OP & $0.86^{*}$ & $0.73^{*}$ & $0.88^{*}$ & $0.76^{*}$ & $0.87^{*}$ & $0.75^{*}$ & $0.82^{*}$ & $0.84^{*}$ & $0.64^{*}$ & $0.53^{*}$ & $0.72^{*}$ & $0.37^{*}$ & 1 \\
\hline
\end{tabular}

*significant at $1 \%$ level of significance $\mathrm{TM}=$ Top Management, $\mathrm{SR}=$ Supplier Relationships, ER $=$ Employee Relations, E\&T $=$ Education and Training, PM = Process Management, QI = Quality Information and Analysis, SP = Strategic Planning, PD = Power Distance, $\mathrm{UA}=$ Uncertainty Avoidance, IND = Individualism, MAS = Masculinity and OP = Organizational Performance

In addition, the correlation coefficient tests the criterion validity. Criterion validity according to Badri and Davis (1995) is to check the extents to which instruments are explain or predict the value of another independent instrument. It is also called external or predictive validity. To achieve this correlation test was done to observe the strength of the relationship between all the constructs using Pearson's $r$ correlation coefficients. Therefore, the convergent validity is established for the all the constructs. On the issue of linearity (linear relationship of variables), Hair et al. (2007) and Pallant (2010) suggest the use of P-P plots to check for the relationship. When the plots show a pattern close to the diagonal line, then it is assumed that a linear relationship exists. A visual inspection of the P-P plots indicated the items from the predictor variables were linearly related to those from the criterion variables.

\subsection{Factor Analysis}

Factor analysis is an interdependence technique and it is essential in several stages of development and assessment of measures. The underlying principle of factor analysis is the data parsimony and data interpretations in which items are condensed into common interrelated and meaningful dimensions (Churchill and Iacobucci, 2006). The primary purpose of factor analysis is to define the underlying structure among the variables in the analysis (Hair et al., 2007).

Before proceeding with the analysis, various criteria must be considered to check the suitability of the study in performing factor analysis. There are two main issues to consider in determining whether a data set is suitable for factor analysis (Pallant, 2010). First, is the sample size; as suggested by Tabachnick and Fidell (2001), the researcher needs to have at least 300 cases for factor analysis, however, a small sample size (e.g., 100 cases) should be sufficient if solutions have several high loading marker variables (above 0.80). Hair et al. (2007) suggest that the researcher generally would not factor analyze a sample of fewer than 50 observations and preferably the sample size should be 100 or larger.

The total number of items to measure all the variables for the current study is 96. For the soft TQM practice the constructs are top management (8 items), Supplier relationship (8 items), employee relations (15 items), education and training (7 items) and Customer focus (6 items). Hard TQM practice consists of three constructs which are process management (4 items), quality information and analysis (11 items) and strategic planning (9 items). The moderator which is the national culture consists of 4 constructs power distance (4 items), uncertainty avoidance (4 items), Individualism (4 items) and Masculinity (4 items). The dependent variable which is organizational performance consists of total of 12 items.

Furthermore, only items with loadings higher than 0.50 on one factor and low cross-loadings were retained for further analysis (Nunnally, 1978). Factor loading is useful to ascertain the convergent and discriminant validity of the scales (Hurley and Hult, 1998). It also specifies the strength of the relationship between items and latent construct. According to Hair et al. (2007), factor loadings of \pm 0.5 or greater are considered practically significant. Generally, in this study, the items were not retained if they: (i) did not load into any factor with a value of 0.5 or greater, (ii) freestanding items (i.e., in one factor there is only one item with high factor loading) and (iii) had cross loading on two factors. The results will be presented as follows. 
Table 3. Factor analysis process for study variables

\begin{tabular}{|c|c|c|c|c|}
\hline $\begin{array}{l}\text { Number of } \\
\text { Extracted Factors }\end{array}$ & $\mathrm{KMO}$ & $\begin{array}{l}\text { Bartlett's } \\
\text { Test of Sphericity }\end{array}$ & $\begin{array}{l}\text { Variance } \\
\text { Extracted }(\%)\end{array}$ & Remarks \\
\hline \multicolumn{5}{|c|}{ Independent Variables soft TQM practices } \\
\hline 5 & 0.941 & 5254 & 69.0 & $\begin{array}{l}\text { Customer focus } 1 \text { and } 4 \text { and supplier } \\
\text { relations } 4 \text { dropped- loaded in the wrong factor }\end{array}$ \\
\hline 5 & 0.939 & 4813 & 69.0 & Education and training 5 dropped-cross loaded \\
\hline 5 & 0.942 & 4675 & 69.6 & Customer 3,5 and 6 dropped-loaded in the wrong factor \\
\hline 4 & 0.942 & 4219 & 68.0 & Employee relations 15 dropped-loaded in the wrong factor \\
\hline 4 & 0.942 & 4083 & 68.0 & Employee relations 5 dropped-cross loaded \\
\hline 4 & 0.941 & 3937 & 68.0 & Final set. 30 items \\
\hline \multicolumn{5}{|c|}{ Independent Variables hard TQM practices } \\
\hline 3 & 0.953 & 2991 & 72.5 & $\begin{array}{l}\text { Quality information and analysis item } 9,10 \text { and } 11 \\
\text { and strategic planning } 2,7 \text { and } 8 \text { dropped-cross loading }\end{array}$ \\
\hline 3 & 0.942 & 1922 & 72.0 & Strategic planning item 1 and 4 dropped-cross loading \\
\hline 3 & 0.937 & 1625 & 73.0 & $\begin{array}{l}\text { Strategic planning item } 5 \text { and quality information and } \\
\text { analysis dropped-wrong factor loading and cross loading }\end{array}$ \\
\hline 3 & 0.927 & 1250 & 75.0 & Final set. 15 items \\
\hline \multicolumn{5}{|c|}{ Moderating Variable (National Culture) } \\
\hline 4 & 0.87 & $979 *$ & 66.0 & $\begin{array}{l}\text { Uncertainty avoidance } 1,3 \text { and } 4 \text { dropped- } \\
\text { cross loaded and low item loaded. }\end{array}$ \\
\hline 4 & 0.852 & $774^{*}$ & 71.0 & $\begin{array}{l}\text { Individualism } 2 \text { and power } 3 \text { dropped- } \\
\text { cross loading and wrong facto loading }\end{array}$ \\
\hline 3 & 0.787 & $498^{*}$ & 68.0 & $\begin{array}{l}\text { Uncertainty } 2 \text { and masculinity } 4 \text { dropped } \\
\text { - cross loading and wrong factor loading. }\end{array}$ \\
\hline 3 & 0.75 & $421^{*}$ & 70.0 & Final set. 9 items \\
\hline \multicolumn{5}{|c|}{ Dependent Variable (the adoption of Programming and performance budgeting } \\
\hline 1 & 0.919 & $1009^{*}$ & 58 & $\begin{array}{l}\text { Total number of items with loading more than } \\
0.5 \text { is } 12 \text { items }\end{array}$ \\
\hline
\end{tabular}

First the KMO results, second the scree plot, third the variance explained and lastly the rotated matrix with the factor loadings. In terms of deciding how many factors to include two criteria will be used namely, scree plot and Eigen value more than 1. Using only one of these two might lead to inclusion of unnecessary factors.

Theoretically it was expected that the measurement items would group into eight variables that were identified in the literature. Due to cross-loadings, the number for the independent variables (factors) decreased to 6 during the stages of the EFA process. The number drops to 6 in the final stage of the EFA process.

The factor analysis was run on three main variables. First, the independent variables which consist of Soft and Hard TQM practices which are formed using 5 and 3 constructs respectively. Second, the moderating variable, the national culture which consists of 4 constructs. Lastly the dependent variable which consists of one construct only. The analysis was done separately for these three variables. Table 3 show the number of factors extracted, the KMO, the Bartlett's test of Sphericity and the variance extracted.

\section{DISCUSSION}

\subsection{Regression Analysis}

Section 3.4 will concentrate on the regression analysis of the proposed framework and to test the hypothesis derived from it. However before delving into the regression analysis there is some critical issue that needs to be addressed.

Table 4 report the regression results of the first model. The result shows that all soft and hard TQM practices are significant and positively related with the organizational performance. The standardized beta shows the direction as well as the strength of the partial correlation between each independent variable and organizational performance. From Table 5 standardized beta for the soft TQM practices indicate that top management has the strongest influence on the organizational performance followed by employee relations, supplier relationship and lastly education and training. Similarly, hard TQM practices standardized beta indicate that strategic planning is the most influential practice followed by quality information and analysis and finally the weakest is process management. 
The tolerance and VIF which test Multicollinearity indicate values higher than 0.2 and less than 10 respectively indicating that the model does not suffer from severe Multicollinearity. In term of the goodness of the model the $\mathrm{R}^{2}$ and the adjusted $\mathrm{R}^{2}$ indicate that 36 and $32 \%$ respectively of the variation in the organizational performance is explained by all the independent variables. In addition, the F-value which indicates the goodness of fit is significant at $1 \%$ pointing out that the model is good. Furthermore to check the two important classical assumption of the model namely, normality and homoscedasticity the three graphs below confirm that the model does not violate any of the classical assumptions.
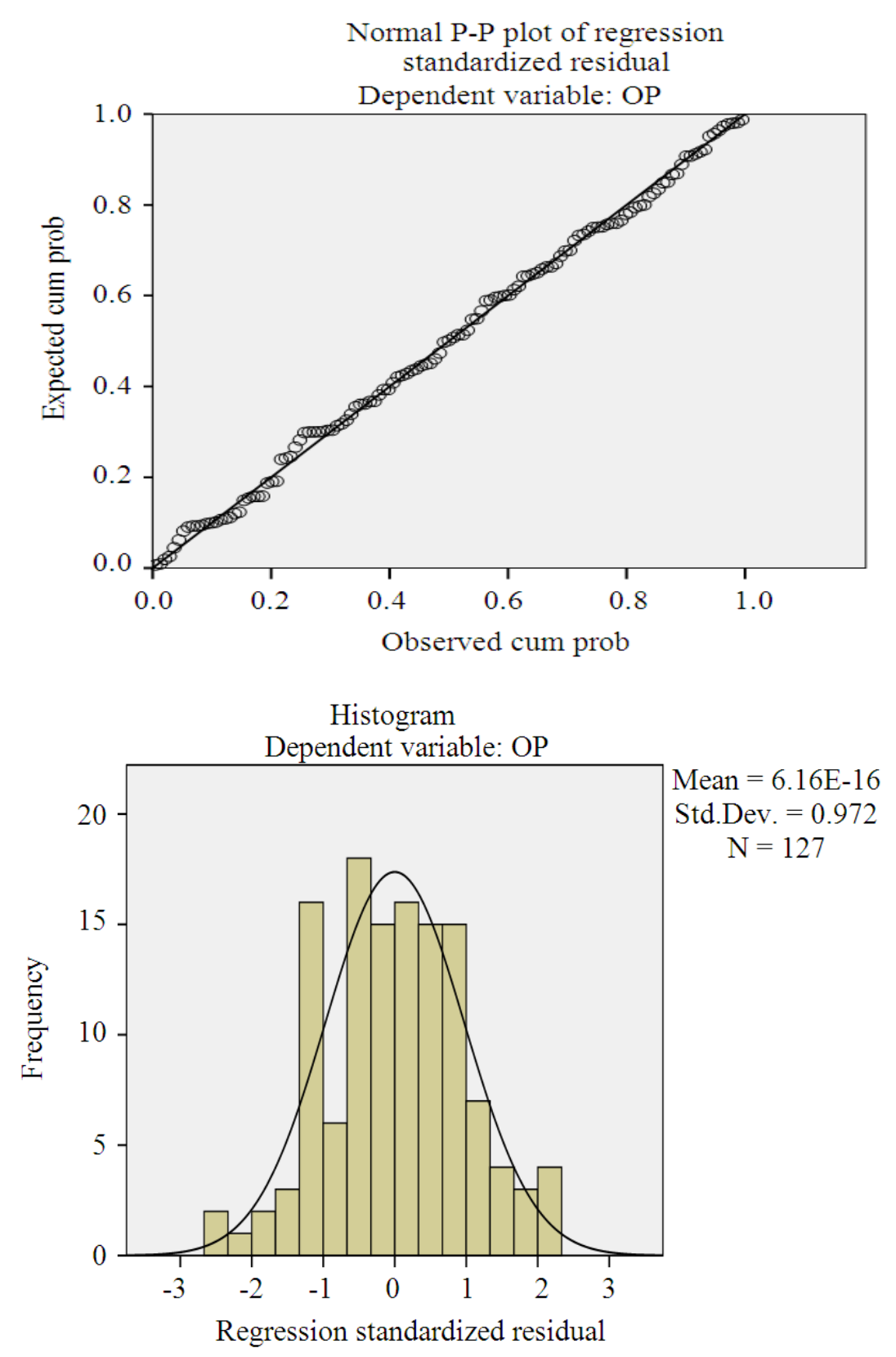

Fig. 2. Model one residual distribution 
Table 4. Rregression result for model 1

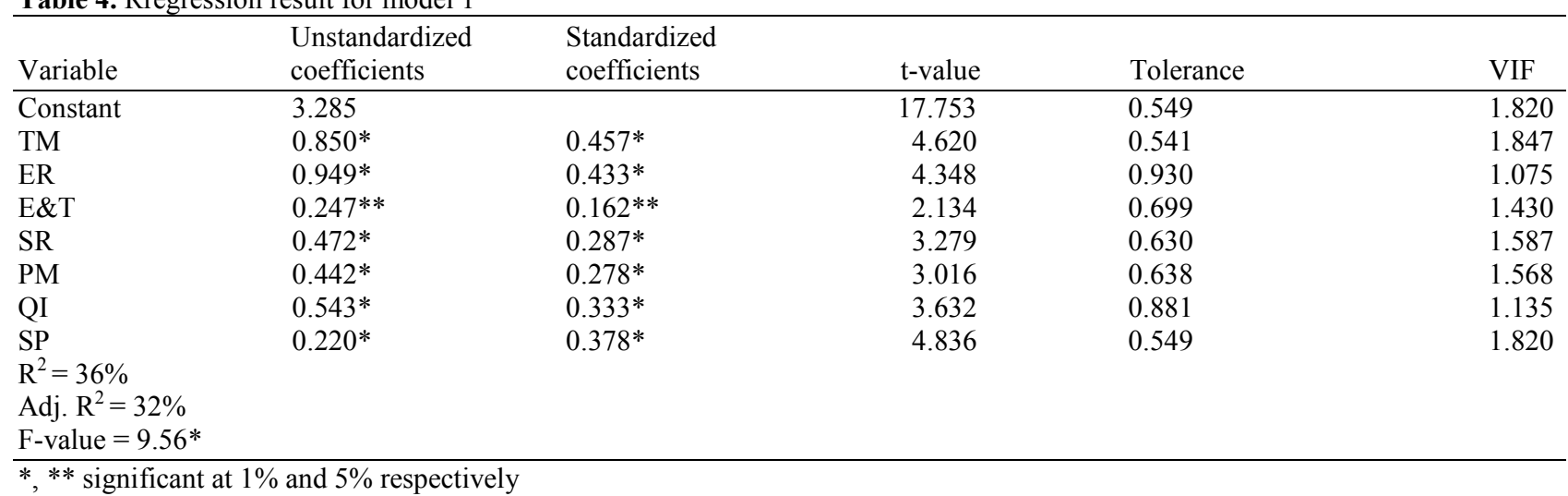

Table 5. Organizational performance mean difference

\begin{tabular}{|c|c|c|c|c|c|c|c|}
\hline \multirow[b]{2}{*}{ Variable } & \multirow[b]{2}{*}{ F-value } & & \multicolumn{5}{|c|}{ Mean difference } \\
\hline & & & Saudi Arabia & Egypt & Turkey & Jordan & Qatar \\
\hline \multirow{5}{*}{$\begin{array}{l}\text { Organizational } \\
\text { performance }\end{array}$} & $22.4^{*}$ & Saudi Arabia & ------ & & & & \\
\hline & & Egypt & $1.07 *$ & ------ & & & \\
\hline & & Turkey & -0.03 & $1.11 *$ & ------ & & \\
\hline & & Jordan & $1.36^{*}$ & 0.29 & $1.39^{*}$ & ------ & \\
\hline & & Qatar & 0.01 & $-1.1^{*}$ & 0.05 & -1.34 & ----- \\
\hline
\end{tabular}

\section{* Significant at $1 \%$}

The histogram show that the residual fall in $+/-3$ standard deviations as seen in Fig. 2 below indicating that the residual of the model is normally distributed. Similarly Fig. 2 which show the P-P plot. According to Pallant (2010) if the observation are lie on the line in the plot this reflect that no major deviations of the residual from normality.

The other classical assumption is homoscedasticity which emphasize that the variance of the error term must be constant and does not vary with different observations.

\subsection{Difference in Organizational Performance}

Section 3.5 will test the hypothesis whether the mean performance across countries are similar or not. The technique that is used to test the mean difference between these countries is one way analysis of variance or one way ANOVA. The result is reported in Table 5 below. The result of testing the hypothesis indicates that there is a significance difference between all these countries in terms of mean of organizational performance. However this does not show which countries is different and by how much. The second part of Table $\mathbf{5}$ shows the significant mean difference between these countries. It is clear that Saudi Arabia has higher and significant mean than Egypt and Jordan but not turkey and Qatar. On the other hand Egypt has significantly higher mean that turkey but significantly lower than Qatar. Lastly, turkey organizational performance is significantly higher than Jordan.

\section{CONCLUSION}

This study was set up to investigate was the mediating effect of National Culture (NC) on two interdependent parts of TQM that Soft-Hard TQM and organizational performance relationship as reflected in the Municipalities in Five developing contries (Egypt, Jordan, Qatar, Saudi Arabia and Turkey). However, Hard TQM, related to the system, tools and techniques, soft quality factors are those elements of TQM deals with long-term natures and is characterized as humanistic intangible factors that are difficult to directly been measured such as top management commitment, customer focus, teamwork, training and empowerment and effective communication. Essentially, this study was greatly motivated by the inconclusive findings, in the recent relevant literature concerning the relationship between Soft Total Quality Management-Hard Soft Total Quality Management (Soft-Hard TQM) and the Organizational Performance (OP). However, the inconclusive conclusions about these relationships (Nair, 
2006) have been an important unresolved issue that needs further examination.

In the study, the results of the relationship between the Soft TQM, Hard TQM, National culture and their association to organizational performance in Municipalities in five developing countries are revealed. Therefore, the recommendation for future studies is to examine these variables in other different developing countries to help determine their impact on other public organization in other countries, as well as to examine if their findings are in line with the current study or not. In addition, other studies have pointed to a difference in the nature of the organizations due to cultural differences between different people and this is a different angle that could be explored in future studies.

\section{REFERENCES}

Badri, M.A. and D. Davis, 1995. A study of measuring the critical factors of quality management. Int. J. Q. Reliab. Manage., 12: 36-53. DOI: 10.1108/02656719510080604

Baron, R.M. and D.A. Kenny, 1986. The moderatormediator variable distinction in social psychological research: Conceptual, strategic and statistical considerations. J. Personality Soc. Psychol., 51: 1173-1182. DOI: 10.1037/0022-3514.51.6.1173

Churchill, G.A. and D. Iacobucci, 2006. Marketing Research: Methodological Foundations. 8th Edn., An Academic Internet Publishers, AIPI, ISBN-10: 1428806113, pp: 264.

Fang, T., 2010. Asian management research needs more self-confidence: Reflection on H (2007) and beyond. Asia Pacific. J. Manage., 27: 155-170. DOI: 10.1007/s10490-009-9134-7

Gudykunst, W.B., Y. Matsumoto, S. Ting-Toomey, T. Nishida and K. Kim et al., 1996. The influence of cultural individualism-collectivism, self construals and individual values on communication styles across cultures. Hum. Commun. Res., 22: 510-543. DOI: 10.1111/j.1468-2958.1996.tb00377.x

Hair, J., W. Black, B. Babin, R. Anderson and R. Tatham, 2007. Multivariate Data Analysis. 1st Edn., Pearson Education India, New Delhi, ISBN-10: 8131715280, pp: 924.

Hall, E.T., 1989. Beyond Culture. 1st Edn., Anchor Books, New York, ISBN-10: 0385124740, pp: 298.

Hofstede, G., 1984. Culture's Consequences: International Differences in Work Related Values (Sage, Beverly Hills, CA). 1st Edn., SAGE Publications, Beverly Hills, ISBN-10: 0803913060, pp: 327.
House, R.J., P. J. Hanges, M. Javidan, P. Dorfman and V. Gupta, 2004. Culture, Leadership and Organizations: The GLOBE Study of 62 Societies, Sage Publications: Thousand Oaks, CA. 1st Edn., SAGE Publications, Thousand Oaks, ISBN-10: 0761924019, pp: 818.

Hurley, R. F. and G.T.M. Hult, 1998. Innovation, market orientation and organizational learning: An integration and empirical examination. J. Market., 62: 42-54. DOI: $10.2307 / 1251742$

Lee, E.T. and J. Wang, 2003. Statistical Methods for Survival Data Analysis. 3rd Edn., John Wiley and Sons, Hoboken, NJ., ISBN-10: 0471458554, pp: 534.

Nair, A., 2006. Meta-analysis of the relationship between quality management practices and firm performance-implications for quality management theory development. J. Operat. Manage., 24: 948975. DOI: $10.1016 /$ j.jom.2005.11.005

Nunnally, J.C., 1978. Psychometric Methods. 1st Edn., McGraw, New York.

Pallant, J., 2010. SPSS Survival Manual: A Step by Step Guide to Data Analysis using SPSS. 1st Edn., McGraw-Hill International, Maidenhead, ISBN-10: 0335242391, pp: 352.

Parsons, T. and A. Edward, 1951. Toward a General Theory of Action.

Rotter, J.B., 1966. Generalized expectancies for internal versus external control of reinforcement'. Psychol. Monographs: General Applied, 80: 1-28. DOI: $10.1037 / \mathrm{h} 0092976$

Samson, D. and M. Terziovski, 1999. The link between TQM practices and organizational performance. Int. J. Q. Reliab. Manage., 16: 226-262. DOI: 10.1108/02656719910223728

Schwartz, S.H., 2008. Cultural Value Orientations: Nature and Implications of National Differences. Hebrew University of Jerusalem.

Sondergaard, M., 1994. Research note: Hofstede's consequences: A study of reviews, citations and replications. Organ. Stud., 15: 447-456. DOI: 10.1177/017084069401500307

Tabachnick, B.G. and L.S. Fidell, 2001. Using Multivariate Statistics. 4th Edn., Allyn and Bacon, Boston, ISBN-10: 0321056779, pp: 966.

Trompenaars, F. and C.H. Turner, 1997. Riding the Waves of Culture: Understanding Cultural Diversity in Business. 2nd Edn., Nicholas Brealey Publishing, London, ISBN-10: 1857881761, pp: 275.

Trompenaars, F., 1993. Riding the Waves of Culture: Understanding Cultural Diversity in Business. 1st Edn., Economist Books, London, ISBN-10: 0850584280, pp: 192. 
Rabiul Islam and Abdullah ALNasser / American Journal of Applied Sciences 10 (10): 1191-1200, 2013

Tung, R.L. and A. Verbeke, 2010. Beyond Hofstede and GLOBE: Improving the quality of cross cultural research. J. Int. Bus. Stud., 41: 1259-1274. DOI: $10.1057 /$ jibs.2010.41
Woolliams, P., 1997. The Trompenaars Database. In: Riding the Waves of Culture: Understanding Cultural Diversity in Business, Trompenaars, F. and C.H. Turner (Eds.), Nicholas Brealey Publishing, London, ISBN-10: 1857881761. 